\title{
Glicoproteína del virus rábico: Estructura, inmunogenicidad y rol en la patogenia
}

\author{
Andrés Ross B., Myriam Favi C. y Abel Vásquez V.
}

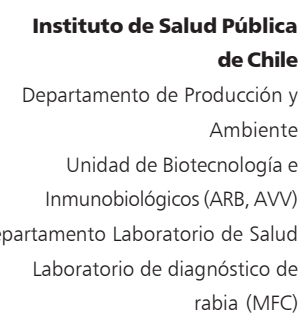

Recibido: 4 de junio de 2007 Aceptado: 26 de noviembre de 2007

Correspondencia a: Abel Vásquez V. avasquez@ispch.cl

\section{Rabies virus glycoprotein: Structure, immunogenicity and pathogenic role}

Rabies glycoprotein is the only exposed protein which is inserted in the viral lipidic envelope. This 65-67 kda protein is a N-glycosilated transmembrane protein forming trimers on the viral surface. It has been identified as the major pathogenicity determinant, playing a role in the budding, viral axonal transport during infection, apoptosis and immune evasion. It is also the major antigen responsible for the protective immune response and it is been used in commercial recombinant vaccines. Its structure, antigenicity and pathogenic role have been well studied, identifying main antigenic sites that have the responsibility for virulence, cellular receptors attachment and epitope acquisition.

Key words: Rabies, glycoprotein, structure, antigenic sites, pathogenic role.

Palabras clave: virus rábico, glicoproteína, estructura, sitios antigénicos, rol patogénico.

\section{Introducción}

$\mathrm{E}$ l virus rábico es un virus ARN de hebra simple, de polaridad negativa y con un tamaño entre 11 y $15 \mathrm{~kb}$. Pertenece a la familia de los Rhabdovirus, género Lyssavirus. Este género consiste en una colección de virus genéticamente relacionados, los que se han adaptado para replicar en el sistema nervioso (SN) de mamíferos ${ }^{1-3}$. Se creía que sólo una especie viral era la responsable de causar enfermedad hasta que se demostró la existencia de al menos seis nuevos genotipos pertenecientes a este género: virus del murciélago australiano, virus Mokola, virus del murciélago Lagos, Duvenage y virus del murciélago europeo tipo 1 y 2, todos los cuales producen una encefalitis clínicamente indistinguible de la rabia clásica y letal, a excepción del virus del murciélago Lagos ${ }^{4,5}$.

El virión posee cuatro proteínas estructurales y una ARN polimerasa. La nucleocápside está formada por el ácido nucleico asociado a tres proteínas: $\mathrm{N}$ o nucleoproteína, $\mathrm{P}$ o fosfoproteína y L o ARN polimerasa ARN dependiente. La glicoproteína $\mathrm{G}(\mathrm{Gp}-\mathrm{G}$ ) del virus rábico es la principal responsable de la patogenicidad viral así como también el antígeno responsable de la inducción de anticuerpos neutralizantes ${ }^{6}$, los que neutralizan la infección in vitro y protegen contra la infección experimental'; así mismo participa en la invasión, transporte y diseminación viral en el tejido infectado ${ }^{8}$.

Estructura. En todos los rhabdovirus la Gp-G corresponde a una proteína trans-membrana tipo I N- glicosilada, la cual forma trímeros de proyecciones (peplómeros) en la superficie viral. Aunque esta proteína es conservada en todos los Rhabdovirus, los distintos géneros comparten un bajo nivel de identidad en la secuencia aminoacídica. Se ha observado una notable conservación de los sitios de glicosilación, dominios antigénicos mayores y de los residuos de cisteína en los puentes di-sulfuro; su localización es única para cada género pero absolutamente conservada dentro del mismo, señalando con esto que los elementos centrales de la estructura de la Gp-G de los Rhabdovirus son conservados?

La Gp-G del virus rábico es una molécula de 65 a 67 kda, que forma aproximadamente 400 proyecciones de peplómeros en la envoltura viral, extendiéndose a 8,3 nm de la membrana lipídica. Está compuesta de 505 aminoácidos, aproximadamente, y posee de dos a cuatro sitios potenciales de $\mathrm{N}$-glicosilación, de los cuales sólo uno o dos son dependientes de la cepa viral, e importantes en el correcto plegamiento de la proteína ${ }^{9,10}$. Al analizar la estructura del gen de la proteína G del virus rábico, los primeros 19 aminoácidos del extremo amino-terminal codificados por esta secuencia representan, probablemente, un péptido señal ya que son predominantemente hidrofóbicos y son posteriormente removidos de la estructura proteica. Un dominio hidrofóbico ininterrumpido de 22 aminoácidos es propuesto como el segmento trans-membrana, el que es fundamental en el correcto plegamiento del ecto-dominio. Desde este último extremo, se extiende una se- 
cuencia de 44 aminoácidos, la que se señala como un dominio hidrofílico citoplasmático, que interactuaría fuertemente con la proteína de la matriz viral (M) y las proteínas de la nucleocápside ${ }^{11,12}$.

La Gp-G adquiere tres estados diferentes, ello involucra un re-arreglo estructural $\mathrm{pH}$ inducido, que modifica la capacidad fusogénica viral, determinando la exposición del dominio de fusión, el que interactúa y desestabiliza las membranas participantes, mecanismo por el cual la nucleocápside es liberada de la vesícula endocítica al citoplasma celular ${ }^{9,10,13}$. Los tres estados corresponden a: estado nativo $(\mathrm{N})$, detectado en la superficie viral a $\mathrm{pH} 7$, responsable de la unión a receptores; estado hidrofóbico activado (A), el cual interacciona con la membrana; y conformación fusogénica inactiva (I), siendo cada uno de estos cambios estructurales totalmente reversibles al ajustar el $\mathrm{pH}$. Entre los pH 6,0 y 5,6 ocurren cambios de conformación dramáticos que involucran la pérdida de la estructura secundaria y terciaria. Bajo $\mathrm{pH}$ 6,7 el virus rábico se vuelve más hidrofóbico permitiendo la interacción con la membrana, es óptimo para la fusión un pH 6,3. Esta última conformación es considerada el estado A. Con $\mathrm{pH}$ de fusión, los sitios contenidos en el segmento del ecto-dominio que compromete los aminoácidos 103-179 se han identificado como los segmentos que interaccionan de manera hidrofóbica con la membrana plasmática, estando en este segmento los aminoácidos histidina $_{148}$ e histidina ${ }_{149}$, los que, al protonarse a un $\mathrm{pH}$ ácido, producen el reordenamiento de la Gp-G, necesario para la interacción y fusión de membranas ${ }^{9,13-15}$.

Se sugiere que el plegamiento de la proteína presenta un $\mathrm{t}_{1 / 2}$ cercano a 20 minutos, con una eficiencia de 70 a $80 \%$, produciéndose una interacción con chaperonas del retículo endoplásmico. La adquisición de la estructura de los sitio antigénicos II y III sería un evento tardío en el plegamiento proteico, comparado a lo que ocurriría en los otros segmentos de la proteína que se pliegan rápidamente ${ }^{16}$. Se han establecido comparaciones entre la secuencia aminoacídica de la Gp-G rábica, específicamente referentes al sitio antigénico II, con neurotoxinas curaromiméticas del veneno de serpiente, ambos ligandos potenciales del nACh-R. La más grande similitud entre ambas ocurre en los residuos que se unen al nACh-R y los aminoácidos 189200 de la Gp-G rábica ${ }^{17,18}$.

Rol en la patogenia. Esta proteína es responsable de la invasión al SN mediante la adhesión del virus rábico a receptores celulares como el receptor nicotínico de acetilcolina ${ }^{19-22}$ moléculas de adhesión celular neuronales $(\mathrm{CD} 56)^{23}$ y el receptor de neurotrofinas $\mathrm{p}^{75}$ $\left(\mathrm{NTR}^{75}\right)^{24}$, los cuales median la endocitosis mediada por receptores, mecanismo por el cual el virus ingresa a la célula ${ }^{6,7}$. Al ser la única proteína viral expuesta, es obvia y ha sido demostrada su participación en la fusión de membranas, mecanismo por el cual la nucleocápside es liberada de la vesícula endocítica al citoplasma celular ${ }^{7,9,10}$. Asociado a esto, la Gp-G del virus rábico interacciona con la nucleocápside mediante su asociación con la proteína M, permitiendo una eficiente yemación de la progenie viral ${ }^{6,25,26}$.

Si bien el flujo axoplásmico viral se ha demostrado ocurrir a través de la interacción de la fosfoproteína con la subunidad LC8 de la cadena liviana de dineina (un componente del complejo de transporte citoplasmático axonal) $)^{27,28}$, este transporte puede también ocurrir prescindiendo del sitio de unión de la fosfoproteína a la subunidad LC8 ${ }^{29}$. Así mismo, se ha demostrado que la sola presencia de la Gp-G rábica es capaz de otorgar neurotropismo a vectores lentivirales, involucrando a esta proteína en el transporte axoplásmico viral $^{30}$.

La apoptosis celular se reconoce como el principal mecanismo lesivo celular mediado por la Gp-G, siendo un factor importante en su desencadenamiento la acumulación de glicoproteína en la membrana citoplasmática $^{31}$. Se ha reportado que, en las cepas patógenas de virus rábico, la restricción en la expresión de la Gp$\mathrm{G}$ contribuye a su patogenicidad. Evidencias in vivo e in vitro sugieren que la expresión de esta proteína es consistentemente inhibida en las neuronas infectadas con cepas patógenas de virus rábico, con lo cual se evade la activación de la respuesta inmune innata ${ }^{6,31-33}$, ya que el proceso de apoptosis desencadena una fuerte respuesta inmune ${ }^{34}$. Evidencia in vitro e in vivo en la detección de ARNm de proteína G y nucleoproteína del virus rábico en cepas atenuadas y altamente patógenas, han demostrado que los niveles de expresión para ambas moléculas de ARNm es similar, sugiriendo que la represión en la expresión de la Gp-G en cepas patógenas no es producto de una tasa de replicación viral distinta o una regulación de la transcripción a nivel de ARNm para esta molécula, sino de una modificación post-traduccional por degradación de proteasas ${ }^{33,35}$.

El desarrollo de mutantes deficientes en Gp-G ha demostrado que estas cepas virales realizan una infección restringida a las neuronas afectadas inicialmente, sin diseminarse a otras neurona ${ }^{36}$. Así mismo, el patrón de distribución en el SN de distintas cepas virales rábicas está dictado por la Gp-G y la cepa viral de la cual deriva ${ }^{35}$.

Antigenicidad e inmunogenicidad. La Gp-G del virus rábico es la responsable de la inducción de anticuerpos, los que neutralizan la infección in vitro y protegen contra la infección experimental ${ }^{7}$.

La inmunogenicidad de la Gp-G depende de su conformación tridimensional, estructura secundaria y ter- 
ciaria de la proteína, la que contribuye a la formación de sitios antigénicos ${ }^{37}$ y modificaciones post-transduccionales como la glicosilación de residuos de asparragina $^{38}$; sin embargo, la utilización de un péptido de glicoproteína ha demostrado ser inmunogénicos ${ }^{39}$. La estructura antigénica de la Gp-G ha sido determinada con el uso de anticuerpos monoclonales específicos. Un sitio antigénico se define como la sobreposición de varios epítopes. Este es el caso de los sitios antigénicos II y III de la Gp-G del virus rábico. Otros epítopes, llamados anteriormente sitios I, IV, V, VI, G1 y sitio menor, han sido también identificados usando los mismos procedimientos ${ }^{40}$. El sitio antigénico II esta constituido por los residuos aminoacídicos 34-42 y 198-200 y el análisis de los fragmentos de la proteína ha evidenciado que los péptidos que contienen los aminoácidos 34-42 están unidos mediante puentes disulfuro con los péptidos de los aminoácidos 198-200. Así, se postuló que este sitio antigénico II resulta del plegamiento proteico que acerca dos regiones separadas del la Gp-G. Las mutantes con sustituciones en el sitio antigénico II, particularmente en el aminoácido 198, son menos patogénicas en animales adultos ${ }^{41}$.

Los estudios identifican al sitio antigénico III de la Gp-G, como el mayor determinante de patogenicidad $^{42,43}$; mutaciones en este sitio reducen la diseminación viral ${ }^{44}$ y la unión a receptores celulares ${ }^{45}$. La estructura del sitio antigénico III es distinta al sitio II, pues su estructura es lineal, extendiéndose desde los aminoácidos 330-3407 . En este sitio, la sola sustitución del aminoácido arginina ${ }_{333}$ por glutamina o glicina, afecta la integridad del sitio antigénico y anula, por completo, la patogenicidad y neurovirulencia en el ratón adulto inmunocompetente, sin importar el sitio de inoculación o dosis viral de desafío ${ }^{29,42}$. Aunque esta mutación anula la patogenicidad, luego de realizar un pasaje viral por un ratón lactante, una única mutación se observó en el aminoácido asparragina ${ }_{194}$ a lisina ${ }_{194}$, lo cual se asoció a un incremento de la patogenicidad, sin que esto se asociara a reversiones en la mutación glutamina $_{333}{ }^{46}$; sin embargo, otros residuos aminoacídicos han sido asociados a neurovirulencia; tal es el caso de los aminoácidos 164-303 en la cepa Nishigahara ${ }^{47}$. Muy cercano a este sitio antigénico III, pero sin sobreponerse, se encuentra el epítope que consta de los aminoácidos 342-343. Mutaciones en este sitio antigénico también han demostrado reducir la diseminación viral y el reconocimiento de receptores celulares involucrados en el reconocimiento e internalización viral $^{40,43}$.

Es así como, hoy en día, la Gp-G del virus rábico es empleada en vacunas recombinantes utilizando vectores virales como virus canary pox (Purevax ${ }^{\circledR}$ Merial, Inc.) y virus vaccinia (Raboral ${ }^{\circledR}$ Merial, Inc.) y en el desarrollo de vacunas $\mathrm{ADN}$ anti-rábicas en ratones ${ }^{48-50}$, $\operatorname{caninos}^{50,51}$, felinos ${ }^{52}$ y primates no humanos ${ }^{53}$. Más aún, la utilidad de esta proteína viral en el diagnóstico rápido de la enfermedad ${ }^{54}$ y caracterización de la respuesta inmune vaccinal ${ }^{55}$ ha comenzado a ser abordada por distintos grupos de investigación, con el objeto de evitar tratamientos innecesarios tras una potencial exposición, así como también para la determinación de anticuerpos neutralizantes anti-Gp-G. Los métodos actualmente existente para el diagnóstico tales como RPC e IFD son costosos, utilizan virus vivo y requieren de mucho tiempo; sin embargo, se ha demostrado que el uso de esta proteína recombinante como antígeno diagnóstico en prueba de ELISA podría minimizar esta problemática ${ }^{54}$. En cuanto a la titulación de anticuerpos neutralizantes, la utilización de esta proteína en el desarrollo de una prueba de ELISA para la detección de anticuerpos anti-Gp-G ha arrojado una sensibilidad y especificidad de 98 y 99\%, respectivamente, indicando que esta prueba es tan sensible y específica como la actualmente recomendada por la OMS para la determinación de anticuerpos neutralizantes, tanto en escenarios pre como postexposición ${ }^{55}$.

El rol de esta proteína viral, la única expuesta en la envoltura, en la diseminación e internalización celular viral y en la patogenia, convierten a este antígeno en un excelente candidato para el desarrollo de inmunobiológicos que permitan prevenir y diagnosticar la enfermedad, así como también caracterizar la respuesta inmune en términos de anticuerpos neutralizantes en circunstancias pre o post-exposición, en un contexto que arroje ventajas comparativas a los métodos actualmente utilizados para tales fines en los ámbitos de seguridad, facilidad y rapidez en la entrega de resultados.

La Sección de Biotecnología e Inmunobiológicos del Instituto de Salud Pública de Chile ha amplificado mediante TR-RPC y clonado en vectores plasmidiales la Gp-G desde un aislado calle cepa L51. Su secuencia de ADN posee $99 \%$ de identidad, y 93\% de identidad en su secuencia aminoacídica (datos no publicados) respecto de lo reportado en la literatura ${ }^{56}$. Las perspectivas en el uso de este gen clonado nos permiten proyectar nuestro trabajo en el desarrollo de nuevas alternativas de inmunobiológicos para el virus de la rabia.

\section{Resumen}

La glicoproteína del virus rábico es la única proteína viral expuesta, encontrándose inserta en la envoltura lipídica. Esta molécula de 65-67 kda corresponde a una proteína trans-membrana $\mathrm{N}$-glicosilada que se dis- 
pone en forma de trímeros en la superficie viral. Ha sido identificada como el mayor determinante de patogenicidad, participando además en procesos de yemación, flujo axonal del virion durante la infección, apoptosis y evasión de la respuesta inmune. Es también el principal antígeno inductor de la respuesta inmune protectora siendo utilizado en vacunas recombinantes comerciales. Su estructura, antigenicidad e implicancias en la patogenia han sido bien estudiadas identificándose los principales sitios antigénicos responsables de la patogenicidad, unión a receptores celulares y formación de epitopos.

\section{Referencias}

1.- Smith J, Orciari L, Yager P, Seidel H, Warner C. Epidemiologic and historical relationships among 87 rabies virus isolates as determined by limited sequence analysis. J Infect Dis 1992; 166: 296-307.

2.- Gould A, Hyatt A, Lunt R, Kattenbelt J, Hengstberger S, Blacksell S. Characterization of a novel lyssavirus isolated from Pteropid bats in Australia. Virus Res 1998; 54: 165-87.

3.- Badrane H, Bahloul C, Perrin P, Tordo N. Evidence of two Lyssavirus phylogroups with distinct pathogenicity and immunogenicity. J Virol 2001; 75: 3268-76.

4.- Rupprecht C, Hanlon C, Hemachudha T. Rabies re-examined. Lancet Infec Dis 2002; 2: 327-42.

5.- Warrell L, Warrell M. Rabies and other lyssavirus diseases.

Lancet Infec Dis 2004; 363: 959-69.

6.- Faber M, Pulmanausahkul R, Hodawadekar S, Spitsin S, Mcgettigan J, Schnell M, et al. Over expression of the rabies virus glycoprotein results in enhancement of apoptosis and antiviral immune response. J Virol 2002; 76: 3374-81.

7.- Walker P, Kongsuwan K. Deduced structural model for animal Rhabdovirus glycoproteins. J Gen Virol 1999; 80: 1211-20.

8.- Jackson A. Rabies pathogenesis. J Neuro Virol 2002; 8: 267-9.

9.- Poian D, Carneiro F, Stauffer F. Viral membrane fusion: is glycoprotein $\mathrm{G}$ of rhabdoviruses a representative of a new class of viral fusion preoteins?. Braz J Med Biol Res 2005; 38: 813-23.

10.- Kankanamge P, Irie T, Shoji J, Tochikura T, Kawai A. Further characterization of the rabies virus glycoprotein produced by virusinfected and $\mathrm{G}$ cDNA-transfected cells using a monoclonal antibody, 1-30-44, which recognizes an acid-sensitive epitope. Microbiol Immunol 2003; 47: 337-49.

11.- Anilionis A, Wunner W, Curtis P. Structure of the glycoprotein gene in rabies virus. Nature 1981; 294: 275-8.

12.- Gaudin Y, Moreira S, Benejean J, Blondel D, Flamand A, Tuffereau C. Soluble ectodomain of rabies virus glycoprotein expressed in eukaryotic cells folds in a monomeric conformation that is antigenically distinct from the native state of the complete, membrane-anchored glycoprotein. J Gen Virol 1999; 80: 1647-56.

13.- Gaudin Y. Rabies virus-induced membrane fusion pathway. J Cell Biol 2000; 150: 60111.

14.- Durrer P, Gaudin Y, Ruigrok R, Graf R, Brunner J. Photolabeling identifies a putative fusion domain in the envelope glycoprotein of rabies and vesicular stomatitis viruses. J Biol Chem 1995; 270: 17575-81.

15.- Maillard A, Gaudin Y. Rabies Virus glycoprotein can fold in two alternative, antigenically distinct conformations depending on membrane-anchor type. J Gen Virol 2002; 83: 1465-76.

16.- Gaudin Y. Folding of rabies virus glycoprotein: epitope acquisition and interaction with endoplasmic reticulum chaperones. J Virol 1997; 71: 3742-50.

17.- Bracci L, Antoni G, Cusi M, Lozzi L, Niccolai N, Petreni S, et al. Antipeptide monoclonal antibodies inhibit the binding of rabies virus glycoprotein and alphabungarotoxin to the nicotinic acetylcholine receptor. Mol Immunol 1988; 25: 881-8.

18.- Lentz T, Wilson P, Hawrot E, Speicher D. Amino acid sequence similarity between rabies virus glycoprotein and snake venom curaremimetic neurotoxins. Science 1984; 226: 847-8.

19.- Lentz T, Burrage T, Smith A, Crick J, Tignor G. Is the acetylcholine receptor rabies virus receptor? Science 1982; 215: 182-4.

20.- Burrage T, Tignor G, Smith A. Rabies virus binding at neuromuscular junctions. Virus Res 1985; 2: 273-89.

21.- Gastka M, Horvath J, Lentz T. Rabies virus binding to the nicotinic acetylcholine receptor alpha subunit demonstrated by virus overlay protein assay. J Gen Virol 1996; 77 : 2437-40.

22. - Castellanos J, Castañeda D, Velandia A, Hurtado H. Partial inhibition of the in vitro infection of adult mouse dorsal root ganglion neurons by rabies virus using nicotinic antagonists. Neurosci Lett 1997; 229: 198200 .
23.- Thoulouze $M$, Lafage $M$, Schaschner $M$, Hartmann U, Cremer H, Lafon M. The neural cell adhesion molecule is a receptor for rabies virus. J Virol 1998; 72: 7181-90.

24.- Langevin C, Jaaro H, Bressanelli S, Fainzilber M, Tuffereau C. Rabies virus glycoproteindisdatrimericdligand for the $\mathrm{N}$ terminal cysteine-rich domain of the mammalian p75 neurotrophin receptor. J Biol Chem 2002; 277: 37655-62.

25.- Mebatsion T, Weiland F, Conzelmann K. Matrix protein of rabies virus is responsible for the assembly and budding of bulletshaped particles and interacts with the transmembrane spike glycoprotein G. J Virol 1999; 73: 242-50.

26.- Faber M, Pulmanausahkul R, Nagao K, Prosniak M, Rice A, Koprowski H, et al. Identification of viral genomic elements responsible for rabies virus neuroinvasiveness. Proc Natl Acad Sci USA 2004; 101: 16328-32.

27.- Jacob Y, Badrane H, Ceccaldi P, Tordo N. Cytoplasmic dynein LC8 interacts with Lyssavirus phosphoprotein. J Virol 2000; 74: 10217-22.

28.- Raux H, Flamand A, Blondel D. Interaction of the rabies virus $\mathrm{P}$ protein with the LC8 dynein light chain. J Virol 2000; 74: 10212 16.

29.- Mebatsion T. Extensive attenuation of rabies virus by simultaneously modifying the dynein light chain binding site in the $\mathrm{P}$ protein and replacing Arg333 in the $G$ protein. J Virol 2001; 75: 11496-502.

30.- Mazarakis N, Azzouz M, Rohll J, Ellard F, Wilkes F, Olsen A, et al. Mitrophanous, K. Rabies virus glycoprotein pseudotyping of lentiviral vectors enables retrograde axonal transport and access to the nervous system after peripheral delivery. Hum Mol Genet 2001; 10: 2109-21.

31.- Prehaund C, Lay S, Dietzschold B, Lafon M. Glycoprotein of non-pathogenic rabies virus is a key determinant of human cell apoptosis. J Virol 2003; 77: 10537-47.

32.- Wang Z, Sarmento L, Wang Y, Li X, Dhingra V, Tseggai $\mathrm{T}$, et al. Attenuated rabies virus activates, while pathogenic rabies virus evades, the host immune responses in central nervous system. J Virol 2005; 79: 12554-65. 
33.- Morimoto K, Hooper C, Spitsin S, Koprowski H, Dietzschold B. Pathogenicity of different rabies virus variants inversely correlates with apoptosis and rabies virus glycoprotein expression in infected primary neurons cultures. J Virol 1999; 73: 510-18.

34.- Restifo N. Building better vaccines: How apoptotic cell death can induce inflammation and activate innate and adaptive immunity. Curr Opin Immunol 2000; 12: 597-603.

35.- Yan X, Mohankumar P, Dietzschold B, Schnell M, Fu Z. The rabies virus glycoprotein determines the distribution of different rabies virus strains in the brain. $\mathrm{J}$ NeuroVirol 2002; 8: 345-52.

36.- Etessami R, Conzelmann K, Fadai-ghotbi B, Natelson B, Tsiang H, Ceccaldi P. Spread and pathogenic characteristics of a Gdeficient rabies virus recombinant: an in vitro and in vivo study. J Gen Virol 2000; 81: 2147-53.

37.- Dietzschold B, Wiktor T, Macfarlan R, Varrichio A. Antigenic structure of rabies glycoprotein: Ordering and immunological characterization of the large $\mathrm{CNBr}$ cleavage fragments. J Virol 1982; 44: 595-602.

38.- Yelverton E, Norton S, Obijeski J, Goeddel D. Rabies virus glycoprotein analogs. Biosynthesis in Escherichia coli. Science 1983; 219: 614-20.

39.- Dietzschold B, Gore M, Marchadier D, Niu $\mathrm{H}-\mathrm{S}$, Bunschoten $\mathrm{H}$, Otvos L, et al. Structural and immunological characterization of a linear virusneutralizing epitope of the rabies virus glycoprotein and its possible use in a synthetic vaccine. J Virol 1990; 64: 3804-9.

40.- Benmansour A, Leblois H, Coulon P, Tuffereau C, Gaudin Y, Flamand A, et al. Antigenicity of rabies virus glycoprotein. J Virol 1991; 65: 4198-203.

41.- Prehaund C, Coulon P, Lafay F, Thiers C,
Flamand A. Antigenic site II of the rabies virus glycoprotein: Structure and role in viral virulence. J Virol 1988; 62: 1-7.

42.- Dietzschold B, Wunner W, Wiktor T, Lopes D, Lafon M, Smith C, et al. Characterization of an antigenic determinant of the glycoprotein that correlates with pathogenicity of rabies virus. Proc Natl Acad Sci USA 1983; 80: 70-4.

43.- Seif I, Coulon P, Rollin P, Flamand A. Rabies virulence: Effect on pathogenicity and sequence characterization of rabies virus mutations affecting antigenic site III of the glycoprotein. J Virol 1985; 53: 926-34.

44.- Tuffereau C, Leblois H, Béne'jean J, Coulon P, Lafay F, Flamand A. Arginine or lysine in position 333 of ERA and CVS glycoprotein is necessary for rabies virulence. Virol 1989; 172: 206-12.

45.- Dietzschold B, Wiktor T, Ntrojanowski J, Macfarlan R, Wunner W, Torres-Anjel M, et al. Differences in cell-to-cell spread of pathogenic and apathogenic rabies virus in vivo and in vitro. J Virol 1985; 56: 12-8.

46.- Faber M, Faber ML, Papaneri A, Bette M, Weihe E, Dietzschold B, et al. A single amino acid change in rabies virus glycoprotein increases virus spread and enhances virus pathogenicity. J Virol 2005; 79: 14141-8.

47.- Takayama-ito M, Ito N, Yamada K, Minamoto N, Sugiyama M. Region at amino acids 164 to 303 of the rabies virus glycoprotein plays an important role in pathogenicity for adult mice. J NeuroVirol 2004; 10: 131-5.

48.- Xiang Z, Spitalnik S, Tran M, Wunner W, Cheng J, Ertl H. Vaccination with a plasmid vector carrying the rabies virus glycoprotein gene induces protective immunity against rabies virus. Virol 1994; 199: 132-40.

49. - Bahloul C, Jacob Y, Tordo N, Perrin P. DNA-based immunization for exploring the enlargement of immunological crossreactivity against the Lyssaviruses. Vaccine 1998; 16: 417-25.

50.- Patial S, Chaturvedi V, Rai A, Saini M, Chandra R, Saini Y, Gupta P. Virus neutralizing antibodies response in mice and dogs with a bicistronic DNA vaccine encoding rabies virus glycoprotein and canine parvovirus VP2. Vaccine 2007; 25: 4020-8.

51.- Perrin P, Jacob Y, Aguilar A, Loza E, Jallet C, Desmezieres E, et al. Immunization of dogs with a DNA vaccine induces protection against rabies virus. Vaccine 1999; 18: 47986.

52.- Osorio J, Tomlinson C, Frank R, Haanes E, Rushlow K, Haynes J, et al. Immunization of dogs and cats with a DNA vaccine against rabies virus. Vaccine 1999; 17: 1109-16.

53.- Lodmell D, Ray N, Prnell M, Ewalt L, Hanlon C, Shaddock J, et al. DNA immunization protects non-human primates against rabies virus. Nat Med 1998; 4: 94979.

54.- Gupta P, Sharma S, Walunj S, Chaturvedi V, Raut A, Patial S, et al Immunogenic and antigenic properties of recombinant soluble glycoprotein of rabies virus. Vet Microbiol 2005; 108: 207-14.

55.- Feyssaguet M, Dacheux L, Audry L, Compoint A, Morize J, Blanchard I, et al. Multicenter comparative study of a new ELISA, PLATELIA ${ }^{\mathrm{TM}}$ RABIES II, for the detection and titration of anti-rabies glycoprotein antibodies and comparison with the rapid fluorescent focus inhibition test (RFFIT) on human samples from vaccinated and non-vaccinated people. Vaccine 2007; 25: 2244-51.

56.- Morimoto K, Hooper D, Carbaugh H, Fu Z, Koprowski H, Dietzschold B. Rabies virus quasi-species: implications forxpathogenesis. Proc Natl Acad Sci USA 1998; 95: 3152-6. 